\title{
THE SHORTENING AND THE AUTOMATION OF PAYMENTS: THE POTENTIALITY OF SMART CONTRACT IN THE AECO SECTOR
}

\author{
GIUSEPPE MARTINO DI GIUDA, PAOLO ETTORE GIANA, and GIULIA PATTINI \\ Dept of ABC, Politecnico di Milano, Milano, Italy
}

\begin{abstract}
The research aims to implement Blockchain in Smart Contract in the design phase to reduce the financial exposition of SMEs. The adoption of Smart Contract, streamlining and accelerating the payments, shows up as a potential revolution of the traditional contractual framework. However, due to the increasing fragmentation and project complexity, the AECO sector is accused of slowness in accommodating and propagating new technologies. The Smart Contract can embed a Blockchain protocol that executes the predefined and agreed clauses by the contracting parties automatically and autonomously. It is a smooth and predictable data-driven process in which, at the after each clause, the payment is automatically issued, ensuring the shortening of payments. In the construction sector, the transaction delay represents a relevant problem that is responsible for disputes and economic disadvantages for the SMEs. Therefore, the paper investigates the process of digitalization starting from Smart Contract. The research is applied to the design phase developed in a BIM environment, pointing out both the advantages and the limitations, especially in the actual legislation. The Smart Contract features allow the entire supply chain to be protected against insolvencies due to late payments, improving process efficiency, and reducing payout times. From the results obtained in this research, the approach could be applied to a real case study and extended to the overall construction process.
\end{abstract}

Keywords: Blockchain, Computational contract, Construction contract, Automated monetary transaction, E-procurement, Risk reduction, Guaranteed payment, BIM.

\section{INTRODUCTION}

The research aims to analyze the application of Smart Contracts in the design phase, identifying the requirements and potentials offered. The reasons for the research lie in the low productivity affecting the construction sector (McKinsey and Company 2017), resulting from The process and contract fragmentation, the hierarchical approach, the imprecise roles definition, and the delays in payments and deliveries (Farmer 2016). The increasing project's complexity hinders the information flow, generating waste, and litigations (Heiskanen 2017).

The presence of information asymmetry influences contract management causes an innate competition among stakeholders by reducing collaboration, supporting the achievement of personal rather than project interests (Mathews et al. 2017). The absence of transparent information sharing feeds the conflict of interest among participants, who tend to interpret contract clauses to reduce their efforts (Huang and Yang 2015). Although the AECO sector has been accused of slow acceptance of digital technologies, the digital transition is the first impetus for change and the progressive adoption of Building Information Modelling (BIM) is improving 
the environment in terms of collaboration, efficiency, and speed. The increasing BIM adoption for the entire project development makes it possible to hypothesize the definition of digital construction contracts, which, based on the progressive model development, are carried out automatically. The payment release is no longer subject to the decision of an individual, but the digital platform is programmed ex-ante in order to manage the process. In the complex construction sector, the possibility of streamlining and automating procedures that traditionally depend on the interaction of multiple participants is an interesting area of research. The goal of this paper is to investigate the Smart Contract adoption in the design phase execution to understand the benefits offered in terms of the speed of the process and compliance with payment times.

\section{DIGITAL TRANSITION IN THE CONSTRUCTION PROCESS: BIM ADOPTION}

Despite its slow adoption, the advent of BIM is proposed as a vehicle to support transparent project development. As the construction process involves a large number of participants, collaboration is a basic requirement. The BIM process pursuit promotes cooperation between the parties by creating a database containing all project information. The BIM model development based on a Common Data Environment (CDE) can, in fact, reduce errors due to document inconsistencies or disconnections through the comprehensible and semantic archiving of information (Antwi-Afari et al. 2018). The BIM-based process intent significantly influences the relationships among the participants (Turk and Klinc 2017) supporting the project visualization, the phase planning, and the communication. The model, constantly updated, stores all information and encourages collaboration. Through a data-driven approach, the information and documents exchange is simplified, facilitating the delivery of the project on time and budget.

On these assumptions, the European Union is committed to issuing regulations to support the adoption of BIM in the construction industry (European Commission 2019).

Table 1. BIM approach: benefits and limitations.

\begin{tabular}{|c|c|}
\hline \multicolumn{2}{|c|}{ BIM approach } \\
\hline Benefits & Limitations \\
\hline Digital visualized prototype & Multiparty aggregation \\
\hline Common Data Environment - CDE & Data reliability and ownership \\
\hline Geometric and semantic information & Data provenance and change tracing \\
\hline
\end{tabular}

Although BIM improves information management, its adoption has shown issues related to data reliability, traceability, and completeness (Nawari and Ravindran 2019a, Tezel et al. 2019). These long-term issues disincentives individuals to collaborate and share information truthfully, with a negative impact on contract management and process performance.

Realized BIM limitations, the research proposes the integration of Blockchain technology that guarantees information trust. If BIM is currently the best solution for collaborative creation and management of data, Blockchain is a possible answer to the problem of collaboration in the design, construction, and management phases. The survey presented, therefore, aims to identify the potentials offered by Blockchain to overcome the issues highlighted.

\section{BLOCKCHAIN AND SMART CONTRACT APPLICATION IN AECO SECTOR}

Blockchain technology belongs to the DLTs (Distributed Ledger Technologies) and offers a data distributed register, ensured by consensus mechanisms implemented by the operating parties. As trustless technology, it provides a transactional system that stores data ensuring truthfulness, 
control, and immutability without the control of a third authority (Lai and Chuen 2018). Blockchain is, therefore, able to integrate the information, procedures, and contracts guaranteeing the trust among the participants (Hunhevicz and Hall 2019). To better understand the Blockchain, its structure and its impact on contract execution should be analyzed (San et al. 2019): the main features can be summarized in (i) distributed database, (ii) process automation, (iii) immutable data and (iv) data provenance (Dakhli et al. 2019).

Blockchain first applications belong to the economic-financial sector (Trevor 2015). However, thanks to its ability to revolutionize multiple industries, the interest and application of the technology have also spread in the government-public sector and the food-beverage one. Since 2016, within these sectors, the main industrial processes to which the Blockchain applies are payment management, document organization, and supply chain coordination (Osservatorio Blockchain and Distributed Ledger 2020). If the Blockchain use supports transactions without recourse to centralized systems, the use of Smart Contract guarantees the execution of the contractual clauses without recourse to legal systems. Since the information stored on Blockchain can be of any kind, contractual documents can also be archived (Huckle et al. 2016). Smart Contracts as protocols based on Blockchain are contracts drawn up in computer language capable of executing the terms established by the contracting parties automatically. The digital contract implementation revolutionizes the traditional contract where clauses are descriptive words contained in the document of the agreement (Mason 2017).

The decentralized system allows the implementation of a Smart Contract as it facilitates relations among the participants and eliminates the need to control the fulfillment of a certain contractual clause (Hughes 2017). Besides, given the Blockchain programmable nature, it is possible to implement self-executing and self-enforcing contracts that allow the direct involvement of the contracting parties without the presence of a third-party authority that verifies, certifies, and implements contractual terms. Due to their computational nature, Smart Contracts offer practical advantages over traditional contracts that can be summarized in (i) transparent process, (ii) unambiguous understanding of the contract terms, and (iii) time efficiency and cost reduction (Tezel et al. 2019). Despite the potential benefits offered by the Blockchain and Smart Contracts, their disruptive nature gives rise to debates on their actual applicability and usefulness. The main obstacles to implementation are identified in (i) the change in human mindset, (ii) the presence of unforeseen events not definable ex-ante, and (iii) the definition of legislation dedicated to its adoption (Rodrigues et al. 2018).

Despite the obstacles listed, Blockchain contributes to the proper process management aimed at cost optimization, data reliability, and process streamlining, thus attracting industry players. Since collaboration and competition are effective when information is shared equally, the Blockchain adoption in the construction industry could be an interesting advantage (Mathews et al. 2017).

\section{THE THEORETICAL APPLICATION OF SMART CONTRACT FOR DESIGN PHASE PAYMENTS}

Although the payment terms and the information reliability are defined in the contractual clauses, the project development is often characterized by a high number of disputes. The increasing project's complexity requires changes in information management technologies (Wang et al. 2017). Even if the recent digital transition supports communication improvement (Ablyazov and Petrov 2019), Information Modeling has highlighted issues related to information trust, discouraging the parties to cooperate in achieving contractual tasks. 
Since the information traceability and the contract execution control are essential to ensure the efficiency of the process, the introduction of distributed technologies is advantageous as it guarantees data reliability. The BIM and Blockchain combination ensures the development of a $\mathrm{CDE}$, no longer centralized but effectively distributed, transparent, and reliable, where information is collected, maintained, and updated (Nawari and Ravindran 2019b). The focus of this paper is kept on the design phase, providing a framework for streamlined and timely payment development.

The presence of a shared database among all participants allows better identification of (i) the project information and (ii) each activity's responsible supervisor. The parties' interactions are recorded on the platform, as well as all the information requirements and design packages that are executed during this first phase development. The BIM model is executed based on guidelines defined by the client. Each design level must be verified and validated, so the model must respect the requirements and rules of the guidelines to allow design progress. At the end of each level execution, the modeling is validated employing code and model checking software programmed on the provisions of the guidelines. This verification process is iterative: at the end of each control cycle, a payment is made to the designers based on the verification obtained.

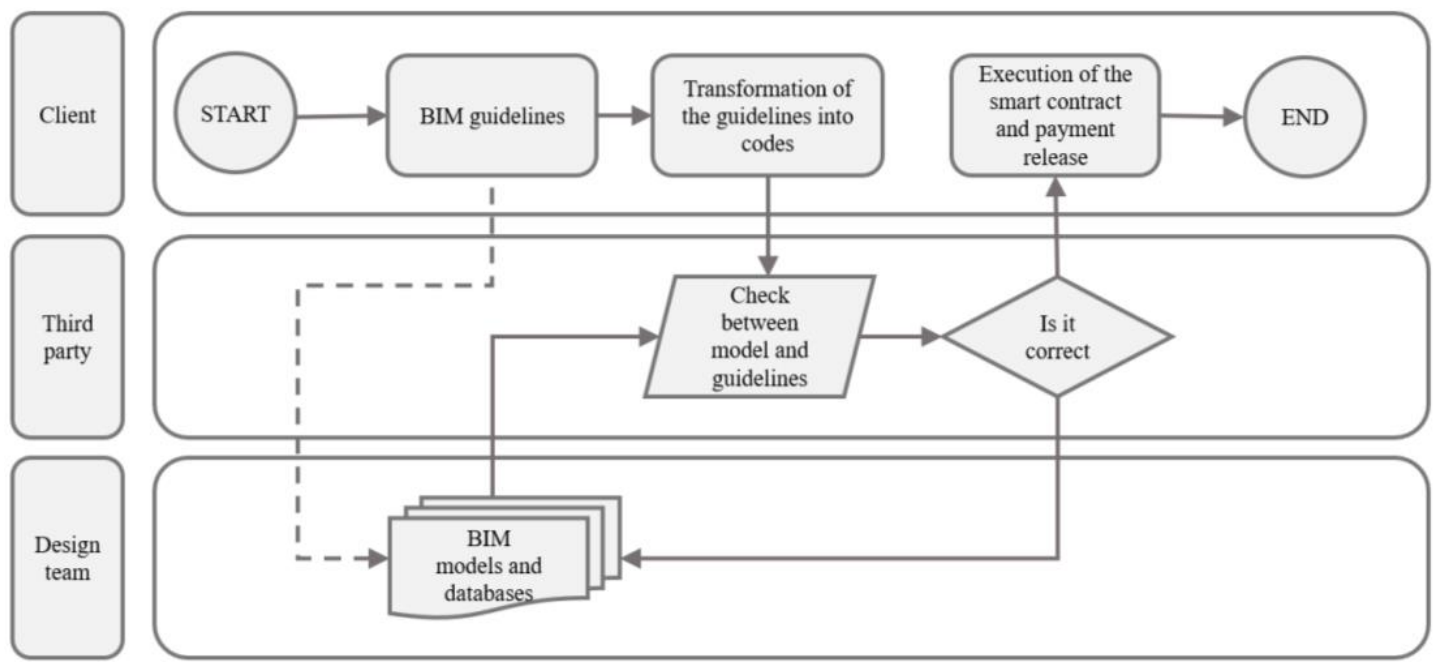

Figure 1. Development of design phase based on Blockchain.

The proposal to carry out the verification of the BIM model development through Blockchain allows the client to check the process compliance transparently and ensures the execution of the contractual clauses, i.e., the release of payments at the end of each validation process. The Blockchain database contains modeling rules and records the progress of the tasks performed by the teams. In this environment, project verification activities are managed by the entire network transparently, ensuring the absence of non-conformities and disputes during the tender phase.

Thanks to the Blockchain, the verification process described can be automated by translating the rules defined in the guidelines into computational language. The modeling rules translated into codes are integrated into the checking software that is thus programmed to extract the information contained in the BIM model and check it against the previously translated rules. The automation of the verification process is, therefore, combined with the contractual performance automation through the use of a Smart Contract. The contractual clauses are programmed to selfexecute at the end of each verification cycle of the design levels. In each model verification 
cycle, the checking software validates guidelines compliance and automatically compares the results obtained with the contractual clauses. The code provides an automatic payment release every time a design stage is approved, which ensures payments incentives for participants to perform the work under the contract. The model delivery is made following the client's requirements and designers are paid through Smart Contract for each end task (Stougiannos and Magneron 2019).

The BIM model based on Blockchain makes it possible to control "who, what and when" at all times, thus making the database the only source of truthful information and the legal basis for any disputes. This integration improves the benefits for the client and all stakeholders in the construction industry (Turk and Klinc 2017). Blockchain adoption implies a willingness to regulate relations and make contractual relations transparent. The Smart Contract application allows stabilizing the contract development by defining codes that produce a certain result developing in the if-then logic. Considering the frequent complaints due to delays or typical nonpayment, the possibility of automating some processes that are traditionally entrusted to interaction and pursued based on decisions of multiple subjects shows an area of experimentation (Stougiannos and Magneron 2019). Construction activities can be divided into smaller work packages in line with Smart Contracts, encouraging the shift from a centralized to a decentralized approach where the contract becomes multiparty (Aste et al. 2017). Typical contract legal nature is radically transformed by ensuring the prevention of litigation (Dakhli et al. 2019).

\section{CONCLUSION AND FURTHER DEVELOPMENT}

As the trust issue in the construction sector is relevant, the presence of a technology that can remove this issue is an important research area. Given the issues related to information management during the BIM process, the Blockchain impact on information flow is significant. The distributed network ensures the information trust, allowing access and control of the data and encouraging participants to commit to the contractual objectives. The proposed research scheme promotes a new approach based on the integration between BIM and Blockchain to automate project review processes and payment procedures. Project participants must trust the Smart Contract, where information and actions undertaken are securely and unalterably recorded. Although significant parts of the design phase can be incorporated into the BIM model and guaranteed by Blockchain, it is unlikely that the entire construction contract can be fully coded considering its long and unpredictable nature. However, the combination of traditional contracts and Smart Contracts coded in the BIM model could provide interesting results. The shift from a centralized to a distributed approach requires both the significant change in mindset and training of the participants and procurement frameworks and governance mechanisms to support the spread of Blockchain in the sector. In addition, the desire to manage the contract through Blockchain, and therefore Smart Contract, requires a structure that contains both provisions supporting the adoption of BIM and short-time clauses adapted to the performance characteristics of the Smart Contract. Despite the criticalities highlighted, the potentials offered by the proposed methodology allows to fully exploit the information of a BIM-based project. In fact, the application of tools for automatic verification of information and accuracy of the project would allow, through the use of the Blockchain, to automate the entire process until complete verification. The definition of best practices following the first uses allows the optimization of the coding of clauses and design activities within the Smart Contract.

\section{References}

Ablyazov, T., and Petrov, I., Influence of Blockchain on Development of Interaction System of Investment 
and Construction Activity Participants, IOP Conference Series: Materials Science and Engineering, 497(1), 0120001, 2019.

Antwi-Afari, M. F., Li, H., Pärn, E. A., and Edwards, D. J., Critical Success Factors for Implementing Building Information Modelling (BIM): A Longitudinal Review, Automation in Construction, 91, 100110,2018

Aste, T., Tasca, P., and Di Matteo, T., Blockchain Technologies: The Foreseeable Impact on Society and Industry, Computer, 50(9), 18-28, 2017

Dakhli, Z., Lafhaj, Z., and Mossman, A., The Potential of Blockchain in Building Construction, Buildings, 9(77), 1-9, 2019

European Commission, European Construction Sector Observatory Building Information Modelling in the EU Construction Sector, March 22, 2019

Farmer, M., Modernise or Die: The Framer Review of the UK Construction Labour Market, 2016.

Heiskanen, A., The Technology of Trust: How The Internet of Things and Blockchain Could Usher in a New Era of Construction Productivity, Construction Research and Innovation, Taylor and Francis, 8(2), 66-70, 2017

Huang, S., and Yang, J., Contracting Under Asymmetric Customer Returns Information and Market Valuation with Advertising-Dependent Demand, European Journal of Industrial Engineering, 9(4), 538-560, 2015

Huckle, S., Bhattacharya, R., White, M., and Beloff, N., Internet of Things, Blockchain and Shared Economy Applications, Procedia Computer Science, 58, 461-466, 2016.

Hughes, D., The Impact of Blockchain Technology on the Construction Industry, 2017.

Hunhevicz, J. J., and Hall, D. M., Managing Mistrust in Construction Using DLT: A Review of Use-Case Categories for Technical Decisions, Proceedings of the 2019 European Conference for Computing in Construction, 1, 100-109, 2019.

Lai, R., and Chuen, D. L. K., Blockchain - From Public to Private, Handbook of Blockchain, Digital Finance, and Inclusion, 2, 145-177, 2018.

Mason, J., Intelligent Contract and the Construction Industry, Journal of Legal Affairs and Dispute Resolution in Engineering and Construction, 9(3), 2017

Mathews, M., Robles, D., and Bowe, B., BIM+Blockchain: A Solution to the Trust Problem in Collaboration? CITA BIM Gathering 2017, November, 2017.

McKinsey and Company, Reinventing Construction: A Route To Higher Productivity, McKinsey and Company, 168, February 2017.

Nawari, N. O., and Ravindran, S., Blockchain and the Built Environment: Potentials and Limitations, Journal of Building Engineering, 25, 100832, 2019a.

Nawari, N. O., and Ravindran, S., Blockchain Technologies in BIM Workflow Environment, 593-602, $2019 \mathrm{~b}$.

Osservatorio Blockchain and Distributed Ledger, Blockchain and Distributed Ledger: Unlocking The Potential of the Internet of Value, 2020.

Rodrigues, B., Bocek, T., and Stiller, B., The Use of Blockchains: Application-Driven Analysis of Applicability, Advances in Computers, 111, 163-198, Elsevier Inc, 2018.

San, K. M., Choy, C. F., and Fung, W. P., The Potentials and Impacts of Blockchain Technology in Construction Industry: A Literature Review, IOP Conference Series: Materials Science and Engineering, 495(1), 2019.

Stougiannos, L., and Magneron, A., BIM, Blockchain and the Smart Construction Contract, BIM and the Future of Collaboration, 1-4, 2019.

Tezel, A., Papadonikolaki, E., and Yitmen, I., Preparing Construction Supply Chains for Blockchain: An Exploratory Analysis, CIB World Building Congress, (June), 17-21, 2019.

Trevor, K., Beyond Bitcoin: Issues in Regulating Blockchain Transactions, Duke Law Journal, 65:569, 569-608, 2015.

Turk, Ž., and Klinc, R., Potentials of Blockchain Technology for Construction Management, Procedia Engineering, 196(June), 638-645, 2017.

Wang, J., Wu, P., Wang, X., and Shou, W., The Outlook of Blockchain Technology for Construction Engineering Management, Frontiers of Engineering Management, 4(1), 67-75, 2017. 